\title{
Dyslipidemia worsens perinatal outcomes in pregnancies with preeclampsia
}

\author{
A dislipidemia piora os resultados perinatais em gestações com pré-eclâmpsia
}

DOI: $10.37111 /$ braspenj.2020353006

Maria Gracyella Ferreira da Silva'

Raphaela Costa Ferreira²

Fabiana Andréa Moura ${ }^{3}$

Alane Cabral Menezes de Oliveira ${ }^{3}$

\section{Unitermos:}

Triglicerídeos. Cesárea. Recém-Nascido Prematuro. Hipercolesterolemia.

\section{Keywords:}

Triglycerides. Cesarean section. Infant, Premature. Hypercholesterolemia.

\section{Corresponding author:}

Alane Cabral Menezes de Oliveira

Faculdade de Nutrição. Universidade Federal de Alagoas - Campus A. C. Simões

BR 104 Norte, Km 96,7 - Tabuleiro dos Martins Maceio, AL, Brazil - CEP 57072-970.

E-mail: alanecabral@gmail.com

\section{Submission:}

May 20, 2020

\section{Accepted for publication}

August 26, 2020

\begin{abstract}
Introduction: Studies have shown that pregnancies with preeclampsia (PE) have greater changes in lipid profile when compared to pregnant women without the disease, which could lead to adverse perinatal outcomes. Thus, the objective of this study is to evaluate the prevalence of dyslipidemia in pregnant women with PE and its relationship with adverse perinatal outcomes. Methods: Cross-sectional study conducted in a capital of northeastern of Brazil in 2017 with pregnant women with PE and their newborns through the application of a standardized form for collection socioeconomic, obstetric, lifestyle, anthropometric and perinatal data, and assessment of the lipid profile [total cholesterol (TC), high density lipoprotein (HDL), low density lipoprotein (LDL) and triglycerides (TG)]. Poisson regression was used to assess the association of dyslipidemia (outcome variable) with the presence of perinatal outcomes (independent variables), when the magnitude of the associations were expressed in prevalence ratio (PR) and their respective $95 \%$ confidence intervals $(95 \% \mathrm{Cl})$, with $\mathrm{p}<0.05$ being considered significant. Results: The prevalence of dyslipidemia in pregnant women with PE was $56.73 \%$, and it was associated with cesarean delivery (PR: $1.52 ; 95 \% \mathrm{Cl}: 1.02-2.26$ and $p=0.039$ ) and preterm births (RP: 1.49 ; $95 \% \mathrm{Cl}: 1.13-1.96$ and $p=0.004)$. Conclusion: The prevalence of dyslipidemia in pregnant women was high in pregnant with PE and increase the prevalence of cesarean delivery and prematurity. Thus, the evaluation of these markers should be observed with greater attention among prenatal care professionals.
\end{abstract}

\section{RESUMO}

Introdução: Estudos têm demonstrado que gestantes com pré-eclâmpsia (PE) apresentam maiores alterações no perfil lipídico quando comparadas a gestantes sem a doença, o que pode levar a desfechos perinatais adversos. Assim, o objetivo deste estudo é avaliar a prevalência de dislipidemia em gestantes com PE e sua relação com desfechos perinatais adversos. Método: Estudo transversal realizado em uma capital do Nordeste do Brasil, em 2017, com gestantes com PE e seus recém-nascidos por meio da aplicação de formulário padronizado para coleta de dados socioeconômicos, obstétricos, estilo de vida, antropométricos e perinatais e avaliação do perfil lipídico [colesterol total (TC), lipoproteína de alta densidade (HDL), lipoproteína de baixa densidade (LDL) e triglicerídeos (TG)]. A regressão de Poisson foi utilizada para avaliar a associação da dislipidemia (variável de desfecho) com a presença de desfechos perinatais (variáveis independentes), quando a magnitude das associações foi expressa em razão de prevalência (RP) e seus respectivos intervalos de confiança de $95 \%$ (IC95\%), com p <0,05 sendo considerado significativo. Resultados: A prevalência de dislipidemia em gestantes com PE foi de $56,73 \%$, estando associada ao parto cesáreo (RP: 1,52; IC 95\%: 1,02-2,26 e $p=0,039$ ) e prematuridade (RP: 1,49; IC 95\%: 1,13-1,96 e $p=0,004$ ). Conclusão: A prevalência de dislipidemia em gestantes foi elevada em gestantes com PE e aumenta a prevalência de parto cesáreo e prematuridade. Assim, a avaliação desses marcadores deve ser observada com maior atenção entre os profissionais da assistência pré-natal.

1. Graduanda em Nutrição pela Faculdade de Nutrição da Universidade Federal de Alagoas (FANUT/ UFAL), Maceio, AL, Brazil.

2. Nutrição pela Universidade Federal de Alagoas (UFAL), Mestre em nutrição e Doutoranda em Ciências da Saúde pela UFAL, Especialista em nutrição clínica e fitoterapia, Instituto de Ciências Biológicas e da Saúde da Universidade Federal de Alagoas (ICBS/ UFAL), Maceio, AL, Brazil

3. Docente da Faculdade de Nutrição da Universidade Federal de Alagoas (FANUT/ UFAL), Maceio, AL, Brazil. 


\section{INTRODUCTION}

It is estimated that preeclampsia (PE), a specific pregnancy syndrome, affects 1-8\% of pregnancies worldwide, being considered the second cause of maternal morbidity and mortality worldwide. In addition, approximately $73 \%$ of hospital admissions are due to gestational hypertensive syndromes, causing a great impact on the health system?.

It is known that multiple factors are involved in the pathophysiology of PE. Thus, recently, a theory called "two-stages theory" that can explain the pathophysiological changes of the disease, where in the first stage there would be placental ischemia caused by poor placentation caused by several factors, among them immunological and genetic factors; and, sequentially, there would be the second stage, which would be caused due to the release into the plasma of molecules derived from the placenta, such as antiangiogenic factors, inflammatory mediators, vasoconstrictor factors, among others, which would lead to an exacerbation of the inflammatory response and a redox imbalance vascular causing endothelial dysfunction².

In this context, considering that endothelial dysfunction is one of the factors related to the pathogenesis of PE and that atherosclerosis has metabolic changes similar to this disease, studies have shown that pregnant women with PE have greater changes in the lipid profile when compared to those without the disease, and report that maternal predisposition to the disease could also be explained by an abnormal lipid metabolism that would lead to endothelial injury ${ }^{3,4}$.

Studies have shown that PE when in association with other diseases or with some altered biomarker already associated with risk, complication or severity, presents worse perinatal outcomes. Like this, different biomarkers have been studied in the scientific community, including ferritin, uric acid, soluble endoglin, among others, in order to predict the risk of complications and / or severity of $\mathrm{PE}^{5}$. Therefore, it is believed that an altered lipid profile can be used as a prognostic marker for $\mathrm{PE}$, as well as a risk factor for the development of the disease, since studies show that dyslipidemia may be involved in the etiopathogenesis of the disease ${ }^{3,6}$.

Thus, the objective of this study is to evaluate the prevalence of dyslipidemia in pregnant women with PE and its relationship with adverse perinatal outcomes.

\section{METHODS}

Cross-sectional study part of a larger research entitled "Characterization of inflammatory biomarkers and redox imbalance in pregnant women with preeclampsia: relationship with nutritional status and with maternal and fetal repercussions" approved by the Ethics and Research Committee (CEP) under process number 35743614.1.0000.5013.
The largest survey included 332 pregnant women with PE. Of these, 208 pregnant women had biochemical data that could be used in the purpose of this research.

The research was conducted in 2017 at capital of northeastern of Brazil with pregnant women with PE and healthy pregnant women and their newborns, and who met the inclusion criteria, which were: absence of other chronic diseases such as diabetes, human immunodeficiency virus (HIV), sickle cell anemia, among others; presence of neurological problems, being excluded those with a smoking habit, due to the methodology of the larger research.

First, a standardized form was applied that included socioeconomic, obstetric, lifestyle, anthropometric and perinatal data. Subsequently, blood was collected by trained professionals, employees of the university hospital itself, considering all the parameters of biosafety for the measurement of lipid profile markers: total cholesterol (TC), high density lipoprotein $(\mathrm{HDL})$, low density lipoprotein (LDL) and triglycerides (TG).

For socioeconomic, lifestyle and prenatal data, the following variables were considered: age: adolescents when $\leq 19$ years old, average age when between 20 and 34 years old, and $\geq 35$ years old; education: it was classified as $<4$ years or $\geq 4$ years of study race: was classified as black or non-black; marital status: single or married; income: $<$ or $\geq$ a minimum wage, minimum wage of 2017 which was $R \$$ 937.00; Occupation: when exercising any activity that generated income; alcoholism: yes or no; start of prenatal care: $1^{\text {st }}$ trimester or $2^{\text {nd }}$ or $3^{\text {rd }}$ trimester, primigravida: when it is the first pregnancy; Previous PE: when had PE in previous pregnancies, and complications during pregnancy: absence or presence.

The anthropometric assessment of pregnant women was performed using the last gestational weight and height collected from the pregnant woman's card to calculate the body mass index (BMI), which was used as the cutoff point for the classification of nutritional status, as established by Atalah et al. 7 . Gestational weight gain was assessed according to the recommendation of the Institute of Medicine ${ }^{8}(\mathrm{IOM})$, which establishes goals for gestational weight gain according to pre-gestational nutritional status.

The cutoff points used to assess changes in serum lipid values were: $\mathrm{TC}>280 \mathrm{mg} / \mathrm{dL} ; \mathrm{HDL}<50 \mathrm{mg} / \mathrm{dL} ; \mathrm{LDL}>160 \mathrm{mg} / \mathrm{dL}$; and TG> $260 \mathrm{mg} / \mathrm{dL}$, these recommendations being specific to pregnant women as recommended by Burrow and Ferris? Non-HDL cholesterol was calculated according to the formula recommended by the Update to the Brazilian Dyslipidemia Guidelines ${ }^{10}$, which defines as therapeutic targets for non-HDL cholesterol the sum of $30 \mathrm{mg} / \mathrm{dL}$ to the LDL cutoff point. Thus, $190 \mathrm{mg} / \mathrm{dL}$ was used as a cutoff point to assess changes in non-HDL cholesterol of pregnant women in this research.

The presence of dyslipidemia (outcome variable in this research) was performed according to the classification of the 
type of dyslipidemia, when present, considering the definition criteria of the Update on the Brazilian Dyslipidemia Guidelines ${ }^{10}$, that is, it was considered as isolated hypercholesterolemia when there was an isolated increase in the LDL, isolated hypertriglyceridemia when there was an isolated increase in $T G$, mixed hyperlipidemia when there was an increase in LDL associated with an increase in TG and low HDL when there was a decrease in $\mathrm{HDL}$ alone or in association with an increase in LDL or TG.

To evaluate perinatal outcomes, the following variables were considered: weight, height, head circumference, Apgar values in the $1^{\text {st }}$ and $5^{\text {th }}$ minutes of life. The weight, length at birth and head circumference were classified using the weight and length curves at birth by Villar et al. ${ }^{11}$, considering the cut points in percentiles according to international standards, of which those with weight below the $10^{\text {th }}$ percentile were classified as small for gestational age (SGA), between the $10^{\text {th }}$ and $90^{\text {th }}$ percentiles classified as adequate for gestational age (AGA) and those weighing more than the $90^{\text {th }}$ percentile, they were classified as large for gestational age (LGA). The same cutoff points were considered for classification of length at birth and head circumference; gestational age at delivery according to criteria proposed by Battaglia and Lubchenco ${ }^{12}$, being classified as: preterm newborns those with $G A<37$ weeks; non-preterm newborns $G A \geq 37$ weeks; Apgar scores in the $1^{\text {st }}$ and $5^{\text {th }}$ minutes of life were considered to assess the health condition of the newborn at birth, in which values $\leq$ 6 for both minutes characterize risk for the newborn and the presence of complications was investigated by analyzing the medical records of mothers and newborns ${ }^{13}$.

All statistical analyzes were performed using the statistical package SPSS (Statistical Package for Social Science) version 20.0, adopting a 95\% confidence level ( $\alpha=0.05$ ). The normality of the distribution was assessed by applying the Kolmogorov-Smirnov test with correction Lilliefors and the homogeneity of variances by the Levene test. Pearson's chi-square test was used to assess the relationship between categorical variables. Student's t test (parametric test) was used to assess the means in the PE group and Mann-Whitney test (nonparametric test). Poisson regression was used to assess the association of dyslipidemia (outcome variable), a variable expressed in a dichotomous manner, with the presence of perinatal outcomes (independent variables). The magnitude of the associations between the outcome variable and the independent variables were expressed in PR and their respective $95 \%$ confidence intervals $(95 \% \mathrm{Cl})$, with $p<0.05$ being considered significant.

\section{RESULTS}

Pregnant women with PE were $25.03 \pm 7.34$ years of age, being $28.02 \%$ adolescents and $13.04 \%$ in advanced age. Most pregnant women with PE were brown / white (88.94\%); had some degree of education (95.74\%); had monthly family income $>1$ minimum wage (72.92\%); work at home (82.21\%); deny alcoholism (89.90\%); did prenatal care (98.08\%); were overweight (67.78\%) and inadequate gestational weight gain $(70.16 \%, 23.56 \%$ being insufficient and $46.60 \%$ excessive), with no significant difference ( $p>0.05$ ) regarding these characteristics according to the presence or absence of dyslipidemia (Table 1).

The means or median and standard deviations or interquartile interval of the lipid profile values of pregnant women with PE were: $214.33 \pm 51.82$ to total cholesterol; 114.43 \pm 38.15 to $\mathrm{LDL}$ fraction; $210.02 \pm 84.56$ to triglycerides fraction; $58.15 \pm 49.9$ to $\mathrm{HDL}$ fraction and $157.25 \pm 50.81$ to non-HDL fraction.

The prevalence of dyslipidemia in pregnant women with PE was $56.73 \%$ ( $n=118$ ), of which low HDL represented the most prevalent $(64.41 \%)$.

Table 2 shows the perinatal outcomes according to the presence or absence of dyslipidemia in the studied group, where their presence increase the prevalence of cesarean deliveries (PR: 1.52; 95\% Cl: 1.02-2.26 and $\mathrm{p}=0.039$ ) and births of premature children (PR: $1.49 ; 95 \% \mathrm{Cl}: 1.13-1.96$ and $p=0.004$ ).

\section{DISCUSSION}

In the present study, one of the first described in the literature in involves dyslipidemia and PE, a high prevalence of dyslipidemia was found in pregnant women with $P E$, and its increases the prevalence of perinatal outcomes as cesarean delivery and the birth of premature children.

Similarly, Jamal et al. ${ }^{14}$ studying pregnant women with PE in Pakistan found a prevalence of dyslipidemia of $59 \%$. In pregnant women without PE, a population study carried out by Smith et al. ${ }^{15}$, in California, found dyslipidemia in $0.31 \%$, whereas in non-pregnant adult women in Brazil the prevalence is $35.1 \%^{16}$. Thus, the present study reinforces the finding that dyslipidemia is more common in pregnant women with PE when compared to pregnant women without the disease and to non-pregnant adult women.

A meta-analysis that evaluated cohort studies concluded that hypertriglyceridemia precedes the development of $\mathrm{PE}^{3}$, which is caused by the hepatic production of very low density lipoproteins (VLDL) rich in TG due to their lipolysis in adipocytes, and by the decrease in VLDL clearence due to the decrease in lipoprotein lipase (LPL) and liver lipase, being the main lipid manifestation observed in pregnancies with dyslipidemia ${ }^{6}$. In this study pregnant women with PE presented higher mean TG levels when compared with pregnant women without the disease, similar to the findings by Jamal et al. ${ }^{14}$ who found an average with pregnant women with the disease in Multan. 
Table 1 - Characterization of pregnant women with pre-eclampsia with and without dyslipidemia assisted at a maternity hospital in Maceio, Alagoas, 2017.

\begin{tabular}{|c|c|c|c|c|c|c|}
\hline Variables & $\begin{array}{c}\text { Total } \\
n=208(100 \%)\end{array}$ & $\begin{array}{c}\text { With } \\
\text { Dyslipidemia } \\
n=118 \\
(56.73 \%)\end{array}$ & $\begin{array}{c}\text { Without } \\
\text { Dyslipidemia } \\
n=90 \\
(43.27 \%)\end{array}$ & OR & IC95\% & $p^{*}$ \\
\hline \multicolumn{7}{|l|}{ Age } \\
\hline$\leq 19$ years & $58(28.02)$ & 35 (29.66) & $23(25.84)$ & 1.228 & $0.663-2.276$ & 0.536 \\
\hline 20-34 years & 122 (58.94) & 68 (57.63) & $54(60.68)$ & 1.00 & & \\
\hline$\geq 35$ years & 27 (13.04) & 15 (12.71) & $12(13.48)$ & 0.947 & $0.419-2.137$ & 1.000 \\
\hline \multicolumn{7}{|l|}{ Black race } \\
\hline Yes & $23(11.06)$ & $12(10.17)$ & $11(12.22)$ & 0.813 & $0.341-1.938$ & 0.661 \\
\hline No & 185 (88.94) & $106(89.83)$ & 79 (87.78) & 1.00 & & \\
\hline \multicolumn{7}{|l|}{ Education } \\
\hline$<4$ years & $8(4.26)$ & $6(5.08)$ & $2(2.86)$ & 2,357 & $0.464-11.964$ & 0.470 \\
\hline$\geq 4$ years & 180 (95.74) & 112 (94.92) & $68(97.14)$ & 1.00 & & \\
\hline \multicolumn{7}{|l|}{ Marital status } \\
\hline Single & 45 (21.63) & 27 (22.88) & $18(20.00)$ & 1.187 & $0.606-2.323$ & 0.734 \\
\hline Married & $163(78.37)$ & 91 (77.12) & $72(80.00)$ & 1.00 & & \\
\hline \multicolumn{7}{|l|}{ Income } \\
\hline$<1 \mathrm{SW}$ & $52(27.08)$ & 30 (28.04) & $22(25.88)$ & 1.116 & $0.587-2.122$ & 0.870 \\
\hline$\geq 1 \mathrm{SW}$ & 140 (72.92) & 77 (71.96) & 63 (74.12) & 1.00 & & \\
\hline \multicolumn{7}{|c|}{ Working outside the home } \\
\hline Yes & $37(17.79)$ & $20(16.95)$ & $17(18.89)$ & 0.876 & $0.429-1.790$ & 0.719 \\
\hline No & $171(82.21)$ & $98(83.05)$ & $73(81.11)$ & 1.00 & & \\
\hline \multicolumn{7}{|l|}{ Primigravid } \\
\hline Yes & $120(57.97)$ & $70(59.32)$ & $50(56.18)$ & 1.138 & $0.652-1.985$ & 0.672 \\
\hline No & $87(42.03)$ & $48(40.68)$ & $39(43.82)$ & 1.00 & & \\
\hline \multicolumn{7}{|l|}{ Smoke } \\
\hline Yes & $21(10.10)$ & $13(11.02)$ & $8(8.89)$ & 1.269 & $0.502-3.206$ & 0.651 \\
\hline No & $187(89.90)$ & 105 (88.98) & $82(91.11)$ & 1.00 & & \\
\hline \multicolumn{7}{|l|}{ Prenatal care } \\
\hline Yes & $204(98.08)$ & $116(98.31)$ & $88(97.78)$ & 1,318 & $0.182-9.542$ & 1.000 \\
\hline No & $4(1.92)$ & $2(1.69)$ & $2(2.22)$ & 1.00 & & \\
\hline \multicolumn{7}{|c|}{ Pregnancy complications } \\
\hline Yes & $68(32.69)$ & $38(32.20)$ & 30 (33.33) & 0.950 & $0.530-1.704$ & 0.882 \\
\hline No & $140(67.31)$ & $80(67.80)$ & $60(66.67)$ & 1.00 & & \\
\hline \multicolumn{7}{|c|}{ Gestational BMI } \\
\hline Low weight & $10(5.15)$ & $3(2.70)$ & 7 (8.43) & 0.302 & $0.076-1.204$ & 0.102 \\
\hline Eutrophy & $43(22.16)$ & 28 (25.23) & $15(18.07)$ & 1.00 & & \\
\hline Overweight & $63(32.47)$ & 41 (36.94) & $22(26.51)$ & 1.624 & $0.872-3.023$ & 0.163 \\
\hline Obesity & 78 (40.21) & 39 (35.13) & 39 (46.99) & 0.611 & $0.342-1.093$ & 0.105 \\
\hline \multicolumn{7}{|l|}{ Weight gain } \\
\hline Insufficient & $45(23.56)$ & $27(25.00)$ & 18 (21.69) & 0.953 & $0.281-3.235$ & 1.000 \\
\hline Adequate & $57(29.84)$ & $29(26.85)$ & $28(33.73)$ & 1.00 & & \\
\hline Excessive & $89(46.60)$ & $52(48.15)$ & 37 (44.58) & 1.180 & $0.665-2.091$ & 0.662 \\
\hline
\end{tabular}

${ }^{*}$ Chi-square test. $\mathrm{p}<0.05$ as significant. $\mathrm{BMI}=$ body mass index; $\mathrm{OR}=$ Odds ratio; $\mathrm{SW}=$ minimum wage. 
Table 2-Association between dyslipidemia and perinatal outcomes in pregnant women with pre-eclampsia assisted at a maternity hospital in Maceio, Alagoas, 2017.

\begin{tabular}{|c|c|c|c|c|}
\hline \multirow[t]{2}{*}{ Variables } & $\begin{array}{c}\text { With } \\
\text { Dyslipidemia }\end{array}$ & $\begin{array}{c}\text { Without } \\
\text { Dyslipidemia }\end{array}$ & \multirow[t]{2}{*}{ PR (IC95\%) } & \multirow[t]{2}{*}{$p^{*}$} \\
\hline & $n=115(56.37 \%)$ & $n=89(43.63 \%)$ & & \\
\hline \multicolumn{5}{|c|}{ Mode of Delivery } \\
\hline Cesarean & $94(81.74)$ & $59(66.29)$ & $1.52(1.02-2.26)$ & 0.039 \\
\hline Normal & $21(18.26)$ & $30(33.71)$ & 1.00 & \\
\hline \multicolumn{5}{|c|}{ Gestational age at birth } \\
\hline Preterm & $40(35.40)$ & 17 (19.32) & $1.49(1.13-1.96)$ & 0.004 \\
\hline No Preterm & $73(64.60)$ & $71(80.68)$ & 1.00 & \\
\hline \multicolumn{5}{|l|}{ Birth weight } \\
\hline SGA & $16(14.41)$ & $8(9.41)$ & $1.16(0.78-1.72)$ & 0.461 \\
\hline AGA & $75(67.57)$ & $62(72.94)$ & 1.00 & \\
\hline LGA & $20(18.02)$ & $15(17.65)$ & $1.03(0.69-1.52)$ & 0.888 \\
\hline \multicolumn{5}{|c|}{ Length at birth } \\
\hline Low & $10(9.90)$ & $7(8.75)$ & $1.01(0.60-1.70)$ & 0.959 \\
\hline Adequate & $69(68.32)$ & $54(67.50)$ & 1.00 & \\
\hline High & $22(21.78)$ & $19(23.75)$ & $0.96(0.65-1.41)$ & 0.830 \\
\hline \multicolumn{5}{|c|}{ Cephalic perimeter } \\
\hline Low & $18(17.65)$ & $8(10.00)$ & $1.37(0.99-1.88)$ & 0.053 \\
\hline Adequate & $48(47.06)$ & $43(53.75)$ & 1.00 & \\
\hline High & $36(35.29)$ & $29(36.25)$ & $0.95(0.69-1.31)$ & 0.761 \\
\hline \multicolumn{5}{|c|}{ Apgar $1^{\text {st }}$ minute } \\
\hline Low & $10(9.43)$ & $10(11.90)$ & $0.93(0.55-1.57)$ & 0.794 \\
\hline Adequate & $96(90.57)$ & $74(88.10)$ & 1.00 & \\
\hline \multicolumn{5}{|c|}{ Apgar $5^{\text {th }}$ minute } \\
\hline Low & $1(0.93)$ & $3(3.53)$ & $0.41(0.07-2.41)$ & 0.323 \\
\hline Adequate & 106 (99.07) & $82(96.47)$ & 1.00 & \\
\hline \multicolumn{5}{|c|}{ Birth complications } \\
\hline Yes & $19(16.67)$ & $7(8.05)$ & $1.05(0.78-1.40)$ & 0.350 \\
\hline No & 95 (83.33) & 80 (91.95) & 1.00 & \\
\hline
\end{tabular}

* Poisson regression adjusted for: age, race, education, marital status, income, paid activity, primigravida, alcoholism, complications during childbirth, gestational BMI, gestational weight. $p<0.05$ as significant. $A G A=$ adequate for gestational age; $L G A=$ large for gestational age; PR = Prevalence ratio; SGA = small for gestational age .

Furthermore, other meta-analysis that aimed to evaluate genes associated with the development of PE found an association of the disease with the LPL gene, where the alteration in the rs268 allele is related to the decrease in LPL activity and associated with development of PE, whose mechanisms by which such an event occurs are not yet described in the literature ${ }^{17}$. However, changing this gene can explain why pregnant women with PE would have higher serum TG levels when compared to those without the disease.

Recently, study evaluated the association between high levels of TG and low levels of HDL in adults, justifying that in the presence of hypertriglyceridemia generates an imbalance in the production of lipoproteins that leads to less production of $\mathrm{HDL}$, this also leads to a higher number of smaller $\mathrm{HDL}$ particles with higher catabolic rates, contributing to even lower HDL-C ${ }^{18}$. These data justify the fact that the most prevalent type of dyslipidemia in our study was low HDL. Another factor that justify it is that the classification of the type of dyslipidemia according to criteria of the Update of the Brazilian Dyslipidemia Guidelines ${ }^{10}$, does not work low HDL in an isolated way like other lipid fractions, that is, pregnant women who had changes in serum levels of HDL associated with changes in other lipid fractions, such as TG, were classified with the type of low HDL dyslipidemia. 
In addition, a multicentric case-control study conducted in eight Colombian cities, which aimed to assess the association between maternal lipids and apolipoproteins with the presence of PE found, in addition to an association between hypertriglyceridemia and the disease, an association between low $\mathrm{HDL}$ and $\mathrm{PE}^{19}$. Other study, conducted in lowa, who evaluated the genetic predisposition of dyslipidemia and the risk of PE, found a greater genetic predisposition for the decrease in $\mathrm{HDL}$ levels associated with the increased risk of $\mathrm{PE}^{20}$.

It is noteworthy that in the context of atherogenic lipoproteins, non-HDL cholesterol, unlike LDL alone, is the one that best reflects the atherogenic potential, which is considered one of the risk factors for cardiovascular events. Another factor to consider is that during inflammatory processes, as observed in these comorbidities, there is an increase in levels of apolipoprotein A and it is more subject to oxidation and uptake by macrophages, when compared to LDL, thus having greater atherogenic potential. Thus, more studies need to analyze the presence of changes in apolipoprotein $A$ and in non-HDL cholesterol in pregnant with PE and dyslipidemia ${ }^{21}$.

In addition to the observed lipid changes, in this research there was a high percentage of overweight and obese pregnant women and almost half of them had dyslipidemia, despite the lack of association between these variables. In a case-control study carried out in Dubai, which aimed to determine the association between dyslipidemia, overweight and the risk of PE, found that, mainly, hypertriglyceridemia was highly correlated with overweight in pregnancies with the disease ${ }^{4}$. In other study, report that in obese pregnant women dyslipidemia is more accentuated which could be justified by the fact that overweight pregnant women have greater difficulties in adapting to the metabolic change characteristic of the gestational period ${ }^{6}$.

As for perinatal outcomes, the present study found an extremely high rate of cesarean deliveries, being even bigger when in the presence of dyslipidemia. These values are higher than that recommended by the World Health Organization ${ }^{22}$ which determines that a percentage of $\mathrm{C}$-sections greater than $10 \%$. It is noteworthy that this mode of delivery can result in maternal and child complications such as perinatal asphyxia, stillbirth, uterine rupture or obstetric fistula ${ }^{22}$.

Furthermore, in the present study, the presence of dyslipidemia also increased the prevalence of prematurity. Similarly, in a study conducted in Beijing found with singleton pregnancy women that hypertriglyceridemia is associated with a higher risk of preterm birth and fetal macrosomia ${ }^{23}$. As dyslipidemia in the gestational period has been recently analyzed, few studies relate this disorder to perinatal outcomes, with preterm delivery being the main outcome treated in the literature ${ }^{15}$.

It is noteworthy that premature births are associated with adversities such as peri-intraventricular hemorrhage, periventricular leukomalacia, prolonged mechanical ventilation, retinopathy of prematurity or bronchopulmonary dysplasia, in addition to abnormalities in neurodevelopment ${ }^{24}$. Thus, more studies need to be carried out observing the association of premature births when both diseases are associated in the gestational period.

With regard to the public health, the high rates of cesarean sections and prematurity cause higher spending on public coffers, since cesarean sections are more expensive, and both outcomes can cause: an increase in the number of days of hospitalization; referral to intensive care units; and higher expenses with medications, anesthetics and professionals ${ }^{25}$.

As for the limiting factors of the research, it is likely that the high rate of cesarean sections observed in this research is related to the high rate of prematurity found. However, our study did not evaluate this relationship. Also, the type of cross-sectional study does not allow precision in the relationship between cause and effect of dyslipidemias in PE, and the non-dosage of apolipoprotein $\mathrm{A}$ hinders further discussion of the findings.

\section{CONCLUSION}

The prevalence of dyslipidemia in pregnant women was high in pregnant with PE and increase the prevalence of cesarean delivery and prematurity.

These data show that it is necessary to assess serum lipid levels as a routine in prenatal care, especially in the group of pregnant with $\mathrm{PE}$, aiming to minimize fetal outcomes caused by the association of both diseases, thus reducing the morbidity and mortality and costs for public health.

\section{ACKNOWLEDGEMENTS}

To the hospital that authorized the conduct of the research, as managers who agreed to participate, a group of researchers and employees involved, and financial support through (PPSUS/FAPEAL/ under number process 60030 000818/2016).

\section{REFERENCES}

1. Mayrink J, Costa ML, Cecatti JG. Preeclampsia in 2018: revisiting concepts, physiopathology, and prediction. Sci World J. 2018;2018:6268276.

2. Gao Q, Tang J, Li N, Liu B, Zhang M, Sun M, et al. What is precise pathophysiology in development of hypertension in pregnancy? Precision medicine requires precise physiology and pathophysiology. Drug Discov Today. 2018;23(2):286-99.

3. Gallos ID, Sivakumar K, Kilby MD, Coomarasamy A, Thangaratinam S, Vatish M. Pre-eclampsia is associated with, and preceded by, hypertriglyceridaemia: a meta-analysis. BJOG. 2013;120(11):1321-32.

4. Sharami SH, Tangestani A, Faraji R, Zahiri Z, Amiri A. Role of dyslipidemia in preeclamptic overweight pregnant women. Iran J Reprod Med. 2012;10(2):105-12. 
5. Zangana JM, Hamadamen AI. Serum uric acid as a predictor of perinatal outcome in women with pre-eclampsia. Int J Med Res Health Sci. 2018;7(3):168-74.

6. Santos APCD, Couto RD. Lipoprotein profile modifications during gestation: a current approach to cardiovascular risk surrogate markers and maternal-fetal unit complications. Rev Bras Ginecol Obstet. 2018;40(5):281-6.

7. Atalah E, Castillo C, Castro R, Aldea A. Proposal of a new standard for the nutritional assessment of pregnant women. Rev Med Chil. 1997;125(12):1429-36.

8. Kasmussen KM, Yaktine AL. Institute of Medicine (US) and National Research Council (US). Committee to Reexamine IOM Pregnancy Weight Guidelines. Weight gain during pregnancy. Washington: National Academies Press; 2009.

9. Burrow GN, Ferris TF. Complicações clínicas durante a gravidez. $4^{\text {th }}$ ed. São Paulo: Roca; 1996.

10. Faludi AA, Izar MCO, Saraiva JFK, Chacra APM, Bianco HT, Afiune Neto A, et al. Atualização da diretriz brasileira de dislipidemias e prevenção da aterosclerose - 2017. Arq Bras Cardiol. 2017;109(2 Supl.1):1-76.

11. Villar J, Ismail LC, Victora CG, Ohuma EO, Bertino E, Altman DG, et al; International Fetal and Newborn Growth Consortium for the $21^{\text {st }}$ Century (INTERGROWTH-2 ${ }^{\text {st }}$ ). International standards for newborn weight, length, and head circumference by gestational age and sex: the Newborn CrossSectional Study of the INTERGROWTH-2 $1^{\text {st }}$ Project. Lancet. 2014;384(9946):857-68.

12. Battaglia FC, Lubchenco LO. A practical classification of newborn infants by weight and gestational age. J Pediatr. 1967;71(2):159-63.

13. American Academy of Pediatrics, Committee on Fetus and Newborn; American College of Obstetricians and Gynecologists and Committee on Obstetric Practice. The Apgar Score. Pediatrics. 2006;117(4):1444-7.

14. Jamal A, Saeed S, Rafiq F, Jamal A. Lipid profile derangements in women with preeclampsia at a tertiary care hospital. PJMHS. 2017;11(2):703-6.
15. Smith CJ, Baer RJ, Oltman SP, Breheny PJ, Bao W, Robinson $\mathrm{JG}$, et al. Maternal dyslipidemia and risk for preterm birth. PloS One. 2018;13(12):e0209579.

16. Malta DC, Szwarcwald CL, Machado ÍE, Pereira CA, Figueiredo AW, Sá ACMGN, et al. Prevalence of altered total cholesterol and fractions in the Brazilian adult population: National Health Survey. Rev Bras Epidemiol. 2019;22(Suppl 02):E190005.

17. Buurma AJ, Turner RJ, Driessen JH, Mooyaart AL, Schoones JW, Bruijn JA, et al. Genetic variants in pre-eclampsia: a metaanalysis. Hum Reprod Update. 2013;19(3):289-303.

18. Girona J, Amigó N, Ibarretxe D, Plana N, Rodríguez-Borjabad C, Heras M, et al. HDL Triglycerides: a new marker of metabolic and cardiovascular risk. Int J Mol Sci. 2019;20(13):E3151.

19. Serrano NC, Guio-Mahecha E, Quintero-Lesmes DC, BecerraBayona S, Paez MC, Beltran M, et al. Lipid profile, plasma apolipoproteins, and pre-eclampsia risk in the GenPE case-control study. Atherosclerosis. 2018;276:189-94.

20. Spracklen CN, Smith CJ, Saftlas AF, Robinson JG, Ryckman KK. Maternal hyperlipidemia and the risk of preeclampsia: a meta-analysis. Am J Epidemiol. 2014;180(4):346-58.

21. Brea A, Hernández-Mijares A, Millán J, Ascaso JF, Blasco M, Díaz A, et al. Non-HDL cholesterol as a therapeutic goal. Clin Investig Arterioscler. 2019;31(Suppl 2):28-33.

22. Betran AP, Torloni MR, Zhang JJ, Gülmezoglu AM, WHO Working Group on Caesarean Section. WHO Statement on Caesarean Section Rates. BJOG. 2016;123(5):667-70.

23. Zheng W, Huang W, Zhang L, Tian Z, Wang T, Zhang T, et al. Changes in serum lipid levels during pregnancy and association with neonatal outcomes: a large cohort study. Reprod Sci. 2018;25(9):1406-12.

24. Fuentefria RDN, Silveira RC, Procianoy RS. Motor development of preterm infants assessed by the Alberta Infant Motor Scale: systematic review article. J Pediat (Rio J). 2017;93(4):328-42.

25. Entringer AP, Pinto M, Dias MAB, Gomes MASM. Costeffectiveness analysis of spontaneous vaginal delivery and elective cesarean for normal risk pregnant women in the Brazilian Unified National Health System. Cad Saude Publica. 2018;34(5):e00022517.

Institution where the study was developed: Faculdade de Nutrição da Universidade Federal de Alagoas (FANUT/ UFAL), Maceio, AL, Brazil.

Conflict of interest: The authors declare that they have no conflicts of interest. 